\title{
Tables and box
}

\section{TABLES}

2.1 Employment rates for men and women and gender employment gap, 1994, 2000 and $2006 \quad 30$

2.2 Women's employment levels by education and age 34

2.3 Women's employment rates with and without children, 2003 36

2.4 Working hours (mothers) and parents' long-hours working, 2004-05

2.5 Fertility rates, 1980-2005 44

2.6 Household structure according to working hours, 2004-05 50

2.7 Time use of employed men and women, 1998-2003 55

2.8 Attitudes of mothers and fathers on work-care prioritisation, 2004

3.1 Formal childcare and hours of education, children 0-12, 2004-05

3.2 Childcare use and formal childcare preferences among mothers of young children in paid work, 2004-05 88

3.3 Costs of childcare to parents, $2004 \quad 93$

3.4 Various estimates of 'effective' employment-protected $\begin{array}{ll}\text { statutory birth-related leaves } & 100\end{array}$

3.5 'Atypical' working hours: parents with children aged 0-15 111

3.6 Statutory rights to flexible working: Germany, the Netherlands and the UK

5.1 Employment rates and usual hours worked in the UK, 1997 and 2007

5.2 Attitudes to women's employment by sex, 1989-2006 education, 2003 and 2007

$\begin{array}{lll}5.4 & \text { Childcare provision, children 0-7, England } & 160 \\ 5.5 & \text { Flexible working practices, 2000, 2003 and } 2006 & 182\end{array}$

\section{$\mathrm{BOX}$}

5.1 Leaves: glossary of terms 